\title{
Korean Cancer Patients' Awareness of Clinical Trials, Perceptions on the Benefit and Willingness to Participate
}

\begin{tabular}{|c|}
\hline 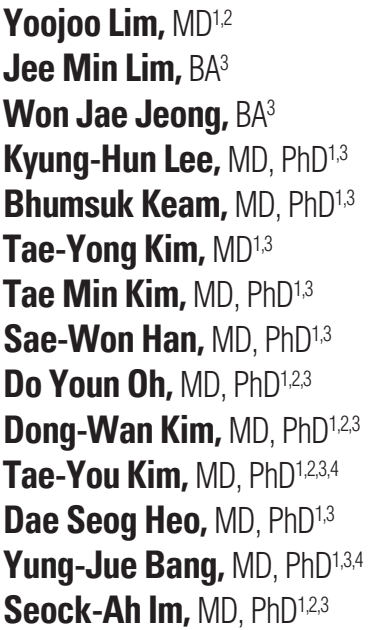 \\
\hline
\end{tabular}

${ }^{1}$ Department of Internal Medicine, Seoul National University Hospital, Seoul, ${ }^{2}$ Translational Medicine Major, Department of Medicine, Seoul National University College of Medicine, Seoul, ${ }^{3}$ Cancer Research Institute, Seoul National University College of Medicine, Seoul, ${ }^{4}$ Department of Molecular Medicine and Biopharmaceutical Sciences, Graduate School of Convergence Science and Technology, Seoul National University, Seoul, Korea
Correspondence: Seock-Ah Im, MD, PhD Department of Internal Medicine, Seoul National University Hospital, 101 Daehak-ro, Jongno-gu, Seoul 03080, Korea Tel: $82-2-2072-0850$

Fax: 82-2-762-9662

E-mail: moisa@snu.ac.kr

Received August 29, 2016

Accepted January 3, 2017

Published Online April 7, 2017

${ }^{*}$ Yoojoo Lim and Jee Min Lim contributed equally to this work

\section{Purpose}

The purpose of this study was to assess current levels of awareness of clinical trials (CTs), perceptions regarding their benefits and willingness to participate to CTs among Korean cancer patients.

\section{Materials and Methods}

From December 2012 to August 2015, we distributed questionnaires to cancer patients receiving systemic anti-cancer therapy at Seoul National University Hospital, Seoul, Korea.

\section{Results}

A total of 397 out of 520 requested patients (76.3\%) responded to the survey. Among the 397 patients, $62.5 \%$ were female and the median age was 52 years. Overall, $97.4 \%$ $(387 / 397)$ answered that they have at least heard of CTs. When asked about their level of awareness, 23.8\% (92/387) answered that they could more than roughly explain about CTs. The average visual analogue scale score of CT benefit in all patients was 6.43 (standard deviation, 2.20). Patients who were only familiar with the term without detailed knowledge of the contents had the least expectation of benefit from CTs $(p=0.015)$. When asked about their willingness to participate in CTs, 56.7\% (225/397) answered positively. Patients with higher levels of awareness of CTs showed higher willingness to participate $(p<0.001)$. Heavily treated patients and patients with previous experience regarding CTs also showed a higher willingness to participate $(p<0.001)$. The perceived benefit of CTs was higher in the group willing to participate $(p=0.026)$.

\section{Conclusion}

The patient's level of awareness regarding CTs was positively related to the positive perception and willingness to participate. Although the general awareness of CTs was high, a relatively large proportion of patients did not have accurate knowledge; therefore, proper and accurate patient education is necessary.

\section{Key words}

Neoplasms, Patients, Clinical trial, Awareness, Perception, Volition 


\section{Introduction}

Clinical trials (CTs) are a crucial part of new drug development. For a new drug to be approved and marketed, the safety and efficacy has to be confirmed by different phases of CTs, which usually involve a large number of patients. Therefore, interest, proper understanding and voluntary consent to participate in CTs are very important to ensure timely and unbiased, successful operation of CTs.

As the molecular understanding of diseases has expanded with improvements in engineering technology, the number of new drugs has also increased at an unprecedented rate, especially in cancer-related fields [1]. Indeed, as of January 2016, the number of CTs registered at ClinicalTrials.gov was 207,521 , representing a 17 -fold increase since 2005 [2]. However, not all drugs are successfully introduced to the market, and results of only $10 \%$ of the trials registered to ClinicalTrials.gov were posted. The low accrual rate is reportedly an important limitation of successful CTs, and several reports on factors influencing the accrual rate have been published [3-5].

In 2008, we collected questionnaires and analyzed cancer patient's awareness of CTs and their willingness to participate [6]. In that study, $82.6 \%$ of patients were familiar with CT, but only $64.7 \%$ were willing to participate. The patients' awareness, perceptions regarding the benefits, and willingness to participate in CTs were influenced by multiple factors including their own health conditions, as well as social and cultural backgrounds. In the last eight years, there have been many changes in Korean society and the medical care environment. Since 2008, South Korea's GDP has increased by roughly $25 \%$, and Korean citizens' spending on medical care has increased by over 50\% [7]. Additionally, people are becoming more interested in leading a healthier life, and as medical knowledge and awareness of CT increases, it is expected that patient views toward CTs will change. Moreover, the number of new drugs and CTs available to Korean patients has increased remarkably. Specifically, the number of CTs in Korea, registered to and approved by the Korean Food and Drug Administration increased by almost two-fold between 2007 and 2013, with investigator-initiated trials increasing almost $640 \%$ [8].

In this context, we surveyed cancer patients to assess their current levels of awareness regarding CTs, as well as their perceived benefit and willingness to participate in CTs.

\section{Materials and Methods}

\section{Patients}

From December 2012 to August 2015, we prospectively surveyed cancer patients who were receiving systemic chemotherapy including targeted therapy at Seoul National University Hospital in Korea. Attending physicians explained the purpose of the questionnaire to the patients at an out-patient clinic and if the patients had will to participate, study procedures were explained in detail by the investigators. Written informed consent to participate in the survey was collected from all participating patients before collecting any study-related information. Questionnaires were collected from the enrolled patients by the co-investigators at the time of the patients' visit to the oncology admission unit, oncology day-care center or out-patient clinic for chemotherapy. Patients were included regardless of the purpose of the anti-cancer treatment or number of lines of therapy they have already received. The study protocol was approved by the Institutional Review Board (IRB) of Seoul National University Hospital (IRB number: 1110-020-380) and was conducted in accordance with the Declaration of Helsinki.

\section{Questionnaire}

The questions were designed to determine the patient's (1) awareness and sources of information for cancer CTs, (2) perceptions regarding the benefits and risks of both CT and conventional therapy, (3) willingness to participate in CT and the reason for participation or nonparticipation, and (4) socioeconomic information. The degree of interest regarding medical information and the awareness of CTs were investigated using questions with 6-scaled descriptions ranging from "1: none/ never heard of" to "6: extremely/know in full detail." The perceived benefits / risks of CT and conventional therapy were collected using a visual analogue scale (VAS) of $0-10$, where a higher score indicates a higher benefit or risk. Demographic information was collected along with the questionnaire, and disease status and treatment history including history of participation to CTs were checked by a medical oncologist by reviewing medical records.

\section{Statistical analysis}

The chi-square test was used to analyze correlations between patient characteristics and their awareness or willingness to participate in CTs. The degree of awareness of CTs collected from the 6-scaled description was converted to scores of $0-10$ for statistical analysis by starting from 0 and increasing in increments of 2 . The scores were reported as 
Table 1. Patient characteristics

\begin{tabular}{|c|c|}
\hline Characteristic & $\begin{array}{l}\text { No. of patients }(\%) \\
(n=397)\end{array}$ \\
\hline Age, median (range, yr) & $52(20-81)$ \\
\hline \multicolumn{2}{|l|}{ Sex } \\
\hline Male & $117(29.5)$ \\
\hline Female & $248(62.5)$ \\
\hline Unknown & $32(8.4)$ \\
\hline \multicolumn{2}{|l|}{ Disease status } \\
\hline Neoadjuvant & $52(13.1)$ \\
\hline Adjuvant & $90(22.7)$ \\
\hline Metastatic, first line & $80(20.2)$ \\
\hline Metastatic, second line & $59(14.9)$ \\
\hline Metastatic, third line & $36(9.1)$ \\
\hline Metastatic, $\geq$ fourth line & $24(6.1)$ \\
\hline Othera)/Unknown & $16(4.2)$ \\
\hline \multicolumn{2}{|l|}{ Diagnosis } \\
\hline Breast & $173(43.6)$ \\
\hline Stomach & $42(10.6)$ \\
\hline Lung & $40(10.1)$ \\
\hline Colorectal & $34(8.6)$ \\
\hline Hepatobiliary/Pancreas & $21(5.3)$ \\
\hline Head and neck/Esophagus & $13(3.3)$ \\
\hline Lymphoma & $8(2.0)$ \\
\hline Other & $26(6.5)$ \\
\hline Multiple primary & $8(2.0)$ \\
\hline Unknown & $32(8.1)$ \\
\hline \multicolumn{2}{|l|}{$\begin{array}{l}\text { Previous history of } \\
\text { clinical trial enrollment }\end{array}$} \\
\hline Yes & $78(19.6)$ \\
\hline No & $287(72.3)$ \\
\hline Unknown & $32(8.1)$ \\
\hline \multicolumn{2}{|l|}{ Marital status } \\
\hline Single & $22(5.5)$ \\
\hline Married & $321(80.9)$ \\
\hline Bereaved & $16(4.0)$ \\
\hline Divorced & $21(5.3)$ \\
\hline Unknown & $17(4.3)$ \\
\hline \multicolumn{2}{|l|}{ Educational degree } \\
\hline College and higher & $191(48.1)$ \\
\hline High school & $135(34.0)$ \\
\hline Middle school & $35(8.8)$ \\
\hline Elementary school & $20(5.0)$ \\
\hline Unknown & $16(4.0)$ \\
\hline \multicolumn{2}{|l|}{ Economic status $^{\text {b) }}$} \\
\hline$>8$ & $32(8.1)$ \\
\hline$>6$ to $\leq 8$ & $40(10.1)$ \\
\hline$>4$ to $\leq 6$ & 77 (19.4) \\
\hline$>2$ to $\leq 4$ & $110(27.7)$ \\
\hline$\leq 2$ & $103(25.9)$ \\
\hline Unknown & $35(8.8)$ \\
\hline
\end{tabular}

Table 1. Continued

\begin{tabular}{|c|c|}
\hline Characteristic & $\begin{array}{l}\text { No. of patients }(\%) \\
(n=397)\end{array}$ \\
\hline \multicolumn{2}{|l|}{ Religion } \\
\hline Christian & $119(30.0)$ \\
\hline Catholic & $65(16.4)$ \\
\hline Buddhist & $78(19.6)$ \\
\hline Atheist/Other & $116(29.2)$ \\
\hline Unknown & $19(4.8)$ \\
\hline \multicolumn{2}{|c|}{ Distance from clinic } \\
\hline$\leq 2 \mathrm{hr}$ & $275(69.3)$ \\
\hline$>2 \mathrm{hr}$ & $107(27.0)$ \\
\hline Unknown & $15(3.8)$ \\
\hline \multicolumn{2}{|c|}{ Possession of private cancer insurance } \\
\hline Yes & $220(55.4)$ \\
\hline No & $152(38.3)$ \\
\hline Unknown & $25(6.3)$ \\
\hline
\end{tabular}

mean point score (standard deviation [SD]). The scores of awareness, benefits and risks with multiple factors were analyzed by the test or one-way analysis of variance to show perceptions based on the benefits of a CT. The paired $t$ test was used to compare the mean VAS scores of clinical benefits and risks of conventional therapy versus CTs within patient groups. All analyses were performed using SPSS for Windows ver. 20 (IBM Corp., Armonk, NY).

\section{Results}

\section{Patient characteristics of responders for the questionnaire}

A total of 520 cancer patients receiving chemotherapy were asked to participate in this study. Among the 520 patients, 397 responded to the questionnaire $(76.3 \%)$. The patient characteristics of the 397 patients are summarized in Table 1. Among the evaluable patients, $62.5 \%$ were female, and the median age was 52 years (range, 20 to 81 years). Most patients were married $(80.9 \%)$ and lived within 2 hours' distance $(69.3 \%)$ from the hospital. In terms of education, $48.1 \%$ of the included patients received equal to or higher than college education. Additionally, 55.4\% answered that they were covered by additional private cancer insurance. Thirty-two patients $(8.4 \%)$ answered the questions regarding awareness and willingness 
Table 2. Perceptions regarding benefits / risks of clinical trials by patient characteristics

\begin{tabular}{|c|c|c|c|c|}
\hline & Benefit & p-value & Risk & p-value \\
\hline \multicolumn{5}{|l|}{ Age group (yr) } \\
\hline$\leq 30$ & $6.60 \pm 2.01$ & 0.239 & $5.30 \pm 0.82$ & 0.222 \\
\hline$>30$ to $\leq 40$ & $6.87 \pm 1.78$ & & $4.92 \pm 1.83$ & \\
\hline$>40$ to $\leq 50$ & $6.42 \pm 1.72$ & & $4.71 \pm 1.84$ & \\
\hline$>50$ to $\leq 60$ & $6.77 \pm 2.16$ & & $4.22 \pm 2.05$ & \\
\hline$>60$ to $\leq 70$ & $6.07 \pm 2.46$ & & $4.77 \pm 2.02$ & \\
\hline$>70$ & $6.10 \pm 1.94$ & & $4.90 \pm 2.20$ & \\
\hline Unknown & $5.71 \pm 1.80$ & & $5.00 \pm 1.74$ & \\
\hline \multicolumn{5}{|l|}{ Sex } \\
\hline Male & $6.41 \pm 1.98$ & 0.196 & $4.78 \pm 1.71$ & 0.253 \\
\hline Female & $6.53 \pm 2.12$ & & $4.54 \pm 2.06$ & \\
\hline Unknown & $5.79 \pm 1.82$ & & $5.10 \pm 1.80$ & \\
\hline \multicolumn{5}{|l|}{ Disease status } \\
\hline Neoadjuvant & $6.78 \pm 1.93$ & 0.373 & $4.36 \pm 2.14$ & 0.533 \\
\hline Adjuvant & $6.61 \pm 2.11$ & & $4.36 \pm 1.90$ & \\
\hline Metastatic, first line & $6.51 \pm 2.16$ & & $4.72 \pm 2.01$ & \\
\hline Metastatic, second line & $6.42 \pm 2.04$ & & $4.73 \pm 2.02$ & \\
\hline Metastatic, third line & $5.64 \pm 2.36$ & & $4.90 \pm 2.01$ & \\
\hline Metastatic, $\geq$ fourth line & $6.17 \pm 2.06$ & & $4.96 \pm 1.43$ & \\
\hline Other ${ }^{a}$ /Unknown & $6.36 \pm 1.81$ & & $4.96 \pm 1.83$ & \\
\hline \multicolumn{5}{|l|}{ Diagnosis } \\
\hline Breast & $6.70 \pm 2.01$ & 0.012 & $4.38 \pm 2.09$ & 0.251 \\
\hline Stomach & $6.65 \pm 2.00$ & & $4.49 \pm 1.85$ & \\
\hline Lung & $5.82 \pm 1.74$ & & $5.03 \pm 1.71$ & \\
\hline Colorectal & $6.10 \pm 2.51$ & & $4.47 \pm 1.91$ & \\
\hline Hepatobiliary/Pancreas & $5.47 \pm 2.65$ & & $5.05 \pm 2.01$ & \\
\hline Head and neck/Esophagus & $6.83 \pm 1.59$ & & $5.58 \pm 1.38$ & \\
\hline Lymphoma & $8.00 \pm 1.16$ & & $5.29 \pm 2.75$ & \\
\hline Other & $6.09 \pm 2.02$ & & $4.96 \pm 1.58$ & \\
\hline Multiple primary & $7.50 \pm 1.41$ & & $5.25 \pm 1.17$ & \\
\hline Unknown & $5.76 \pm 1.79$ & & $5.00 \pm 1.71$ & \\
\hline \multicolumn{5}{|c|}{ Previous history of clinical trial enrollment } \\
\hline Yes & $6.86 \pm 2.03$ & 0.039 & $3.99 \pm 2.16$ & 0.003 \\
\hline No & $6.38 \pm 2.08$ & & $4.82 \pm 1.86$ & \\
\hline Unknown & $5.76 \pm 1.79$ & & $5.00 \pm 1.71$ & \\
\hline \multicolumn{5}{|l|}{ Marital status } \\
\hline Single & $6.52 \pm 2.09$ & 0.828 & $4.72 \pm 1.90$ & 0.555 \\
\hline Married & $6.46 \pm 2.04$ & & $4.76 \pm 1.84$ & \\
\hline Bereaved & $5.79 \pm 2.55$ & & $4.43 \pm 2.34$ & \\
\hline Divorced & $6.50 \pm 1.79$ & & $4.13 \pm 2.22$ & \\
\hline Unknown & $6.33 \pm 2.54$ & & $4.00 \pm 2.28$ & \\
\hline \multicolumn{5}{|l|}{ Educational degree } \\
\hline College or higher & $6.61 \pm 1.78$ & 0.079 & $4.78 \pm 1.85$ & 0.477 \\
\hline High school & $6.50 \pm 2.12$ & & $4.51 \pm 2.05$ & \\
\hline Middle school & $5.64 \pm 2.63$ & & $4.37 \pm 1.84$ & \\
\hline Elementary & $5.93 \pm 2.76$ & & $5.19 \pm 2.07$ & \\
\hline Unknown & $5.55 \pm 2.51$ & & $4.30 \pm 2.16$ & \\
\hline
\end{tabular}


Table 2. Continued

\begin{tabular}{|c|c|c|c|c|}
\hline & Benefit & p-value & Risk & p-value \\
\hline \multicolumn{5}{|l|}{ Economic status $^{\text {b) }}$} \\
\hline$>8$ & $7.19 \pm 1.74$ & 0.079 & $5.13 \pm 2.40$ & 0.681 \\
\hline$>6$ to $\leq 8$ & $6.25 \pm 1.66$ & & $4.81 \pm 1.66$ & \\
\hline$>4$ to $\leq 6$ & $6.72 \pm 1.90$ & & $4.54 \pm 1.85$ & \\
\hline$>2$ to $\leq 4$ & $6.43 \pm 1.92$ & & $4.71 \pm 1.86$ & \\
\hline$\leq 2$ & $5.99 \pm 2.33$ & & $4.57 \pm 2.04$ & \\
\hline Unknown & $6.70 \pm 2.58$ & & $4.35 \pm 1.90$ & \\
\hline \multicolumn{5}{|l|}{ Religion } \\
\hline Christian & $6.53 \pm 2.12$ & 0.458 & $4.56 \pm 1.91$ & 0.193 \\
\hline Catholic & $6.14 \pm 2.28$ & & $5.21 \pm 1.83$ & \\
\hline Buddhist & $6.75 \pm 1.87$ & & $4.59 \pm 2.18$ & \\
\hline Atheist/Others & $6.32 \pm 1.92$ & & $4.56 \pm 1.79$ & \\
\hline Unknown & $6.09 \pm 2.55$ & & $4.10 \pm 2.38$ & \\
\hline \multicolumn{5}{|c|}{ Distance from clinic } \\
\hline$\leq 2 \mathrm{hr}$ & $6.42 \pm 1.99$ & 0.557 & $4.66 \pm 1.99$ & 0.939 \\
\hline$>2 \mathrm{hr}$ & $6.53 \pm 2.19$ & & $4.68 \pm 1.78$ & \\
\hline Unknown & $5.80 \pm 2.49$ & & $4.44 \pm 2.24$ & \\
\hline \multicolumn{5}{|c|}{ Private cancer insurance } \\
\hline Yes & $4.46 \pm 1.99$ & 0.076 & $6.65 \pm 2.00$ & 0.023 \\
\hline No & $5.01 \pm 1.82$ & & $6.18 \pm 2.07$ & \\
\hline Unknown & $4.24 \pm 1.89$ & & $5.94 \pm 2.39$ & \\
\hline
\end{tabular}

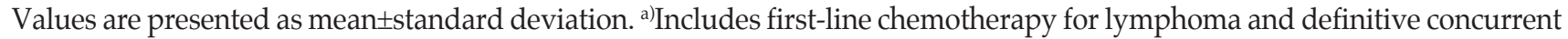
chemoradiotherapy for head and neck cancer, ${ }^{\text {b) }}$ Thousands of United States dollars per month.

to participate in CTs but did not complete their demographic information.

Breast cancer was the most common cancer type $(43.6 \%)$, followed by gastric cancer $(10.6 \%)$ and lung cancer $(10.1 \%)$. At the time of the survey, 199 patients $(52.5 \%)$ were receiving chemotherapy for recurred or metastatic cancer, while $35.8 \%$ were receiving chemotherapy for neoadjuvant/adjuvant purposes. One hundred and fifty-seven (39.5\%) answered that they have been recommended to participate in any CTs by their physicians during their treatment course. At the time of the survey, 78 patients $(19.6 \%)$ had already experienced CT.

In terms of the basal knowledge and interest regarding general medical information, 55 responders $(13.9 \%)$ answered that they were "extremely interested," $34(8.6 \%)$ answered "very interested." One hundred seventy (42.8\%) answered "fairly interested," whereas $77(19.4 \%)$ answered "not much interested," 39 (9.8\%) answe-red "minimum interest only," and four $(1.0 \%)$ answered "none at all." The routes in which the patients received medical information were mass media $(49.2 \%)$, the internet $(33.3 \%)$, physicians or nurses $(21.0 \%)$, or friends and family $(12.3 \%)$.

\section{Cancer patients' awareness of CTs}

When patients were asked about their awareness of CTs, $97.4 \%$ of the patients $(387 / 397)$ answered that they had heard of CT before (scale $\geq 2$ ). Of those, 20 patients (5.2\%) answered that they could explain in full detail what CTs are (scale 6), 72 (18.6\%) answered they could explain CTs in rough detail (scale $5)$, and 134 patients (34.6\%) answered they understand what it is but cannot explain it to others (scale 4). Additionally, 70 $(18.1 \%)$ answered that they have only a rough idea (scale 3 ), while 81 patients $(20.9 \%$ ) answered that they had heard of CT but do not know in detail (scale 2). Regarding the source of information of CTs, 37.5\% of the patients (149/397) answered that they had gathered information from their physicians / nurses, and 34.3\% (136/397) answered mass media including $\mathrm{TV}$, newspapers and internet (multiple answers allowed).

Female gender $(p=0.032)$, higher economic status $(p=0.021)$, higher educational degree $(\mathrm{p}<0.001)$, and prior history of CT enrollment $(p=0.013)$ were positively associated with increasing level of awareness of CT. Moreover, the mean point scores of the awareness in patients whose answer to the source of information included physicians/nurses were significantly higher than the scores of those who did not receive the infor- 
Table 3. Perceived benefits and risks of clinical trials in association with levels of awareness of clinical trials

\begin{tabular}{|c|c|c|c|c|}
\hline & Benefit & p-value & Risk & p-value \\
\hline Never heard of & $7.56 \pm 2.01$ & 0.015 & $4.67 \pm 2.18$ & 0.167 \\
\hline Heard of the term, but do not know content & $6.05 \pm 2.45$ & & $4.62 \pm 2.03$ & \\
\hline Rough idea only & $6.08 \pm 1.81$ & & $5.08 \pm 1.84$ & \\
\hline Understand, but cannot explain & $6.29 \pm 2.00$ & & $4.60 \pm 1.74$ & \\
\hline Can explain in rough detail & $7.03 \pm 1.94$ & & $4.61 \pm 2.02$ & \\
\hline Can explain in full detail & $7.00 \pm 2.00$ & & $3.68 \pm 2.65$ & \\
\hline
\end{tabular}

Values are presented as mean \pm standard deviation.

mation from their physicians / nurses (6.3 [SD, 2.27] vs. 5.1 [SD, $2.12], \mathrm{p}<0.001)$. Patients who could answer the question regarding the stage of their disease, whether correctly or not, also answered more confidently about the awareness of CTs than those who did not or could not answer the question ( $\mathrm{p}=0.002)$. The awareness of CTs was in modest positive correlation with interest in general health information (Spearman's $r=0.374, p<0.001$ ). Possession of private insurance, age, marital status, and travel distance to the hospital were not associated with the awareness of CTs. Moreover, whether the patient was receiving chemotherapy for curative or palliative aim, or the number of regimens the patient had received before survey were not associated with level of awareness.

\section{Perception of the benefits and risks of CTs}

In the survey of the perception of CTs using VAS scale, patients gave a mean value of 6.43 (SD, 2.01) for the benefit and 4.42 (SD, 1.94) for the risk of CTs. The perceived benefits and risks of CTs in association with other patient characteristics are given in Table 2. The patients who have already participated in any CTs before the survey had higher expectations of benefit (6.86 [SD, 2.03] vs. 6.38 [SD, 2.08], p=0.039), and safer perception of the CTs $(3.99$ [SD, 2.2] vs. 4.82 [SD, 1.86], $\mathrm{p}=$ 0.001 ).

The mean scores describing the benefits and risks of conventional therapy were 6.52 (SD, 1.92) and 4.42 (SD, 2.12), respectively, with no significant difference in perception of benefit or risk between $C T$ and conventional therapy $(p=0.315$ and $\mathrm{p}=0.052$, respectively).

When the perceived benefits and risks were analyzed in relation to the level of awareness of CTs, patients who were only familiar with the term without any knowledge of contents had the least expectation of benefit from CTs ( $\mathrm{p}=0.015)$. While patients with higher confidence in their awareness of CTs showed higher expectation of benefits, the patients who were not aware of CTs at all answered the highest scores for the benefit. However, no significant difference between the groups in the level of perceived risk was observed ( $\mathrm{p}=0.167$ ). The average VAS scores of perception of benefits and risks according to awareness are given in Table 3.

\section{Willingness to participate in CTs}

Among the 397 patients, 225 (56.7\%) answered that they would participate in the CTs. The most common reason for willingness to participate was "the opportunity to receive the most up-to-date treatment" (59.6\%), followed by "physician recommendation" $(25.8 \%)$, and "financial benefits of treatment" (11.1\%). On the other hand, among patients who were unwilling to participate in $\mathrm{CTs}$, the most common reason was "because the effects of CTs are not proven yet" (44.1\%), followed by "fear of side-effects" (32.1\%), and "I don't want to be a guinea pig" (15.8\%). Heavily treated patients showed more willingness to participate in CTs $(p<0.001)$. The patients who have experienced CTs before the survey also showed a higher willingness to participate $(\mathrm{p}<0.001)$. Overall, patients who did not complete the questions showed lower willingness to participate. The percentages of patients' willingness to participate in CTs in association with other patient characteristics are given in Table 4.

Patients with higher levels of awareness of CTs were more willing to participate $(p<0.001)$. The average VAS points of perception of the benefits of CTs were higher in the group willing to participate in CTs $(6.65$ [SD, 2.05] vs. 6.14 [SD, 2.04], $\mathrm{p}=0.026$ ). The percentage of patients showing willingness to participate and their perception of the benefits and risks of $\mathrm{CTs}$, in association with the level of awareness of CTs, are shown in Fig. 1. There were no significant differences between the willing and the unwilling group in perceived risks of CTs, or in perceived benefits or risks of conventional therapy.

\section{Actual participation of the patients in CTs}

During the period, an average of 109 studies were available for enrollment at Seoul National University Hospital. We fol- 
Table 4. Willingness of patients to participate in cancer clinical trials

\begin{tabular}{|c|c|c|}
\hline & Willingness to participation (\%) & p-value \\
\hline \multicolumn{3}{|l|}{ Age group (yr) } \\
\hline$\leq 30$ & $3 / 10(30.0)$ & 0.471 \\
\hline$>30$ to $\leq 40$ & $21 / 40(52.5)$ & \\
\hline$>40$ to $\leq 50$ & $55 / 96(57.3)$ & \\
\hline$>50$ to $\leq 60$ & $67 / 116(57.8)$ & \\
\hline$>60$ to $\leq 70$ & $46 / 80$ (57.5) & \\
\hline$>70$ & $15 / 24(62.5)$ & \\
\hline Unknown & 18/31 (58.1) & \\
\hline \multicolumn{3}{|l|}{ Sex } \\
\hline Male & $60 / 117$ (51.3) & 0.638 \\
\hline Female & $146 / 248(58.9)$ & \\
\hline Unknown & 19/32 (59.4) & \\
\hline \multicolumn{3}{|l|}{ Disease status } \\
\hline Neoadjuvant & $19 / 52(36.5)$ & $<0.001$ \\
\hline Adjuvant & $36 / 88(40.9)$ & \\
\hline Metastatic, first line & $53 / 80(66.2)$ & \\
\hline Metastatic, second line & $37 / 59(62.7)$ & \\
\hline Metastatic, third line & $28 / 36(77.8)$ & \\
\hline Metastatic, $\geq$ fourth line & $25 / 28(89.3)$ & \\
\hline Othera)/Unknown & $26 / 51(51.0)$ & \\
\hline \multicolumn{3}{|l|}{ Diagnosis } \\
\hline Breast & $97 / 173(56.1)$ & 0.368 \\
\hline Stomach & $29 / 42(69.0)$ & \\
\hline Lung & $23 / 40(57.5)$ & \\
\hline Colorectal & $19 / 34(55.9)$ & \\
\hline Hepatobiliary/Pancreas & $14 / 21(66.7)$ & \\
\hline Head and neck/Esophagus & $4 / 13(30.8)$ & \\
\hline Lymphoma & $4 / 8(50.0)$ & \\
\hline Other & $12 / 26(46.2)$ & \\
\hline Multiple primary & $5 / 8(62.5)$ & \\
\hline Unknown & $18 / 32(56.2)$ & \\
\hline \multicolumn{3}{|c|}{ Previous history of clinical trial enrollment } \\
\hline Yes & $69 / 78(88.5)$ & $<0.001$ \\
\hline No & $138 / 287(48.1)$ & \\
\hline Unknown & $18 / 32(56.2)$ & \\
\hline \multicolumn{3}{|l|}{ Marital status } \\
\hline Single & $11 / 22(50.0)$ & $<0.001$ \\
\hline Married & $184 / 321(57.3)$ & \\
\hline Bereaved & $13 / 16(81.2)$ & \\
\hline Divorced & $13 / 21(61.9)$ & \\
\hline Unknown & $4 / 17(23.5)$ & \\
\hline \multicolumn{3}{|l|}{ Educational degree } \\
\hline College or higher & $111 / 191(58.1)$ & $<0.001$ \\
\hline High school & $83 / 135$ (61.5) & \\
\hline Middle school & $19 / 35(54.3)$ & \\
\hline Elementary school & $7 / 20(35.0)$ & \\
\hline Unknown & $5 / 16(31.2)$ & \\
\hline
\end{tabular}


Table 4. Continued

\begin{tabular}{|c|c|c|}
\hline & Willingness to participation ( $\%)$ & p-value \\
\hline \multicolumn{3}{|l|}{ Economic status $^{\text {b) }}$} \\
\hline$>8$ & $17 / 32(53.1)$ & $<0.001$ \\
\hline$>6$ to $\leq 8$ & $20 / 40(50.0)$ & \\
\hline$>4$ to $\leq 6$ & $40 / 77$ (51.9) & \\
\hline$>2$ to $\leq 4$ & $65 / 110(59.1)$ & \\
\hline$\leq 2$ & $66 / 103(64.1)$ & \\
\hline Unknown & $17 / 35(48.6)$ & \\
\hline \multicolumn{3}{|l|}{ Religion } \\
\hline Christian & $74 / 119(62.2)$ & $<0.001$ \\
\hline Catholic & $36 / 65(55.4)$ & \\
\hline Buddhist & $46 / 78(59.0)$ & \\
\hline Atheist/Other & $63 / 116(54.3)$ & \\
\hline Unknown & 6/19 (31.6) & \\
\hline \multicolumn{3}{|c|}{ Distance from clinic } \\
\hline$\leq 2 \mathrm{hr}$ & $161 / 275(58.5)$ & $<0.001$ \\
\hline$>2 \mathrm{hr}$ & $60 / 107(56.1)$ & \\
\hline Unknown & $4 / 15(26.7)$ & \\
\hline \multicolumn{3}{|c|}{ Private cancer insurance } \\
\hline Yes & $122 / 220(55.5)$ & $<0.001$ \\
\hline No & $95 / 152(62.5)$ & \\
\hline Unknown & $8 / 25(32.0)$ & \\
\hline
\end{tabular}

a)Includes first-line chemotherapy for lymphoma and definitive concurrent chemoradiotherapy for head and neck cancer,

b) Thousands of United States dollars per month.

A

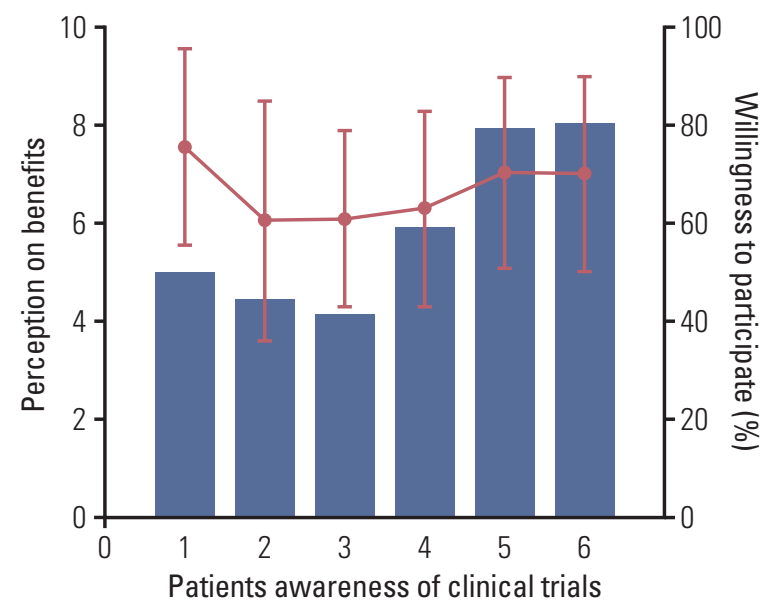

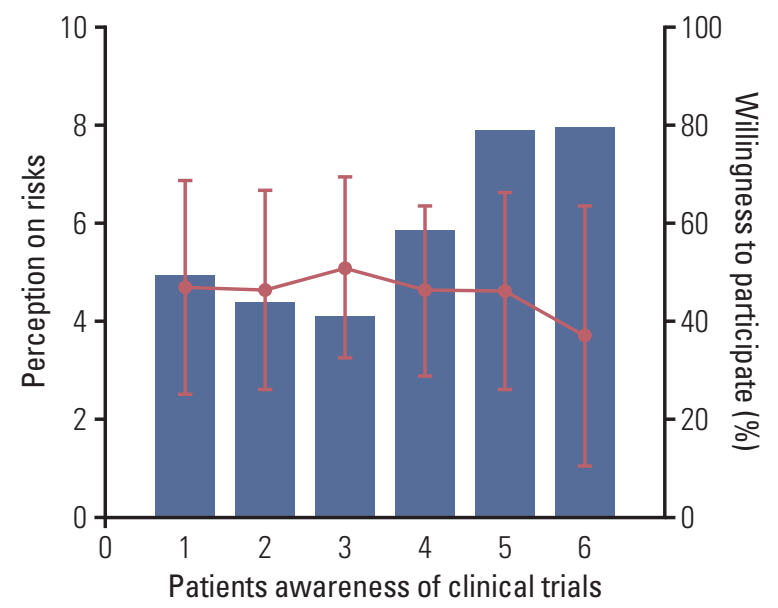

Fig. 1. Cancer patients' willingness to participate in clinical trials relative to level of awareness and perceived benefits/risks of clinical trials. (A) Cancer patients' awareness of clinical trials and willingness to participate relative to perceived benefits (red line: perceived benefit; blue blocks: willingness to participate). (B) Cancer patients' awareness of clinical trials and willingness to participate relative to perceived risks (red line: perceived risk; blue blocks: willingness to participate). (A, B) Patients' awareness of clinical trials: 1, never heard of; 2, heard of clinical trial but do not know in detail; 3, rough idea of only; 4, understand, but cannot explain; 5, can roughly explain; 6, know in full detail. 
lowed up the 222 of the patients who participated in this survey earlier during the collection period, and had more than one year of follow-up time after completion of the survey. Out of the 222 patients, $30(13.5 \%)$ were actually enrolled in trials after the survey. Additionally, 23 of the 30 patients (76.7\%) were those who showed willingness to participate in CTs, while the other seven either answered no or gave no answer.

\section{Discussion}

In our study, we surveyed cancer patients receiving chemotherapy to assess the current levels of awareness of CTs and perceptions regarding the benefits/risks of CTs and finally to assess the willingness of the patients to participate in cancer CTs. While $97.4 \%$ of the surveyed patients answered that they were at least not unfamiliar with CTs, only 5.2\% answered that they were confident with their knowledge. Interestingly, the patients with vague knowledge of CTs had the most doubt about the benefit of the CTs. Overall, 59.4\% of the patients answered positively to the question asking if they were willing to participate in CTs when offered. Additionally, patients with higher confidence of awareness of CTs showed higher willingness to participate.

A low accrual rate has often been identified as an important barrier against successful conduction of CTs [9-12]. It has been reported that only approximately $3 \%-5 \%$ of adult cancer patients enroll in CTs [13]. Understanding and overcoming the patient factor is important to overcoming this barrier. The patients' awareness and understanding of CTs, which are the important factors with potential improvability, have been a subject of interest, and a few studies have been conducted among different populations [14-17]. A number of previous studies have reported positive correlation of patient awareness with the willingness to participate, although some inconsistency still remains. Lara et al. [18] conducted a survey of the residents of California and reported that there was a positive correlation between the respondent awareness of cancer CTs and the willingness to participate. On the other hand, there was a Korean study in 2012 that reported discrepancies between the awareness and the willingness to participate [19]. A summary and recommendations from the National Cancer Institute-American Society of Clinical Oncology Cancer Trial Accrual Symposium suggested that, with existing literature evidence, raising general awareness about CTs alone may not be sufficient to improve accrual; however, the report went on to recommend education of patients and the community about CTs using culturally appropriate materials that considered the patients' point of view [20].

We reported a considerably high percentage of patients having at least heard of CTs (97.4\%). The high proportion being at least familiar with CTs may be related to the fact that the respondents in our patients were all cancer patients receiving chemotherapy. Lara et al. [18] reported that $69 \%$ of the respondents answered that they had heard the term "clinical trial" before; however, their survey had included not only cancer patients, but also their friends and family, and even a small proportion of general public. However, the percentage of patients having at least heard of CTs in this study is still higher than the result reported in our study in 2008, which was $82.6 \%$ [6]. The general increase in awareness may be at least in part explained by the actual increase in the number of CTs available to cancer patients [8]. With improvements in cancer research and new drug development, the number of CTs available has recently expanded rapidly. Indeed, the average number of cancer CTs available for enrollment on any given day at our institution, which is one of the largest university hospitals with a cancer center in Korea, has increased from 47 in 2008 to 110 in 2015.

The results of this study revealed a positive correlation between the patient's awareness and their willingness to participate. These results are in accordance with several previously reported western studies [18]. However, the willingness to participate observed in our report was not much higher than that observed in other reports considering the high percentage of awareness of CTs in our cohort, although consent rates reported in previous studies varied widely [3]. Furthermore, no definite improvement in willingness was observed from our previous study in 2008.

Interestingly, we found that the expectation of benefit from CTs of patients with only a rough idea of CTs was even lower than that of patients without any knowledge of CTs at all. Additionally, although the percentage of patients showing willingness to participate in CTs gradually increased in line with the level of awareness, reaching more than $80 \%$ among patients with a relatively higher understanding of CTs, the percentage of patients with a lower level of understanding that were willing to participate was still not very different from that of patients with no knowledge of CTs at all. A possible explanation for this may be that an accurate or confident level of understanding, rather than any level of awareness of CTs, is important to improving the positive perception and willingness to participate. In our study, patients who answered that they have gathered most of the information from their doctors/nurses answered the question regarding the level of awareness of CTs with higher confidence. These results suggest that active patient education, especially by their physicians and nurses, to provide patients with unbiased accurate information and help them properly understand CTs is important. Proper education may eventually 
lead to improvement in the accrual rate in future CTs.

This study has limitations in that it was conducted at a single center, and focusing only on cancer patients receiving chemotherapy. Moreover, we were not able to include all of the target patients during the study period, which may have led to bias in the study population. Moreover, it is possible that patients with negative attitudes towards any research, including CTs, may have not agreed to participate in this survey. Even among those who agreed to participate in the survey, patients who skipped any of the questions showed less willingness to participate in CTs. This implies a possibility that the results may be skewed from the actual reality towards positive attitudes. As these caveats are one of limitations of collecting questionnaires from large populations, we chose to include and reveal the patients who skipped any of the questions; however, this necessitates that caution be taken when interpreting the results. Despite the limitations, our center is one of the largest cancer centers in Korea, and one of the centers conducting the highest number of cancer CTs. Therefore, the results of this study were based on an important group of cancer patients treated in Korea.
Overall, this research shows the significance and importance of supplying patients with accurate and detailed information regarding the CTs to increase their willingness to participate. As the numbers of novel drugs increase, it will be important to understand the mindset of patients in order to perform CTs. The results presented herein will help predict patients' future attitudes toward CTs in Eastern countries.

\section{Conflicts of Interest}

Conflict of interest relevant to this article was not reported.

\section{Acknowledgments}

This research was partly supported by the Seoul National University Hospital Research Fund (grant number 30-2016-0110) and by the Priority Research Centers Program and Basic Science Research Program through the National Research Foundation of Korea (NRF), funded by the Ministry of Education, Science and Technology (2009-0093820), Republic of Korea.

\section{References}

1. CenterWatch. FDA approved drugs for oncology [Internet]. Boston, MA: CenterWatch; c2016 [cited 2016 Jun 28]. Available from: https:// www.centerwatch.com/drug-information/fdaapproved-drugs / therapeutic-area/12/ oncology.

2. ClinicalTrals.gov. Trends, charts, and maps [Internet]. Bethesda, MD: U.S. National Institutes of Health; c2016 [cited 2016 Jun 28]. Available from: https://clinicaltrials.gov / ct2 / resources/trends.

3. Caldwell PH, Hamilton S, Tan A, Craig JC. Strategies for increasing recruitment to randomised controlled trials: systematic review. PLoS Med. 2010;7:e1000368.

4. Ross S, Grant A, Counsell C, Gillespie W, Russell I, Prescott R. Barriers to participation in randomised controlled trials: a systematic review. J Clin Epidemiol. 1999;52:1143-56.

5. Ford JG, Howerton MW, Lai GY, Gary TL, Bolen S, Gibbons $\mathrm{MC}$, et al. Barriers to recruiting underrepresented populations to cancer clinical trials: a systematic review. Cancer. 2008;112: 228-42.

6. Kim JW, Kim SJ, Chung YH, Kwon JH, Lee HJ, Chung YJ, et al. Cancer patients' awareness of clinical trials, perceptions on the benefit and willingness to participate: Korean perspectives. Br J Cancer. 2008;99:1593-9.

7. Trading Economics. South Korea GDP [Internet]. New York, NY: Trading Economics; c2016 [cited 2016 Jun 28]. Available from: http://www.tradingeconomics.com/ south-korea/gdp.

8. Shim BY, Park SH, Lee S, Kim JS, Lee KE, Kang YK, et al. Current status and challenges of cancer clinical trials in Korea.
Cancer Res Treat. 2016;48:20-7.

9. Tejeda HA, Green SB, Trimble EL, Ford L, High JL, Ungerleider RS, et al. Representation of African-Americans, Hispanics, and whites in National Cancer Institute cancer treatment trials. J Natl Cancer Inst. 1996;88:812-6.

10. Lovato LC, Hill K, Hertert S, Hunninghake DB, Probstfield JL. Recruitment for controlled clinical trials: literature summary and annotated bibliography. Control Clin Trials. 1997;18: 328-52.

11. Haidich AB, Ioannidis JP. Effect of early patient enrollment on the time to completion and publication of randomized controlled trials. Am J Epidemiol. 2001;154:873-80.

12. Ehrlich PF, Newman KD, Haase GM, Lobe TE, Wiener ES, Holcomb GW. Lessons learned from a failed multi-institutional randomized controlled study. J Pediatr Surg. 2002;37: 431-6.

13. Comis RL, Miller JD, Aldige CR, Krebs L, Stoval E. Public attitudes toward participation in cancer clinical trials. J Clin Oncol. 2003;21:830-5.

14. Sood A, Prasad K, Chhatwani L, Shinozaki E, Cha SS, Loehrer LL, et al. Patients' attitudes and preferences about participation and recruitment strategies in clinical trials. Mayo Clin Proc. 2009;84:243-7.

15. Wallington SF, Luta G, Noone AM, Caicedo L, Lopez-Class M, Sheppard V, et al. Assessing the awareness of and willingness to participate in cancer clinical trials among immigrant Latinos. J Community Health. 2012;37:335-43. 
16. Li JY, Yu CH, Jiang Y. Participation in cancer clinical trials as viewed by Chinese patients and their families. Oncology. 2010;79:343-8.

17. Bazarbashi S, Hassan A, Eldin AM, Soudy H, Hussain F. Awareness and perceptions of clinical trials in cancer patients and their families in Saudi Arabia. J Cancer Educ. 2015;30: 655-9.

18. Lara PN Jr, Paterniti DA, Chiechi C, Turrell C, Morain C, Horan $N$, et al. Evaluation of factors affecting awareness of and willingness to participate in cancer clinical trials. J Clin
Oncol. 2005;23:9282-9.

19. Lee SJ, Park LC, Lee J, Kim S, Choi MK, Hong JY, et al. Unique perception of clinical trials by Korean cancer patients. BMC Cancer. 2012;12:594.

20. Denicoff AM, McCaskill-Stevens W, Grubbs SS, Bruinooge SS, Comis RL, Devine P, et al. The National Cancer InstituteAmerican Society of Clinical Oncology Cancer Trial Accrual Symposium: summary and recommendations. J Oncol Pract. 2013;9:267-76. 